\title{
O corpo-voz entre
}

\section{The body-voice in between}

Angelene Lazzareti ${ }^{1}$ Mirna Spritzer ${ }^{2}$ 


\section{Resumo}

Fruto de estudos realizados no âmbito do Programa de Pós-Graduação em Artes Cênicas da Universidade Federal do Rio Grande do Sul, pelas autoras, a presente reflexão aborda os aspectos da voz (proferida e escutada) em sua potencialidade enquanto produtora de expressão e articuladora de sentido e presença. $O$ encontro entre voz, palavra e escuta é discutido a partir de estudos da filosofia e do teatro sobre os pensamentos de José Gil, Gaston Bachelard, Roland Barthes, Ingrid Pelicori, Christoph Wulf, Jacques Derrida e Mladen Dolar.

Palavras-chave: Voz; escuta; corpo; entre; ator

\section{Abstract}

Result of research and studies developed at the Programa de Pós-Graduação em Artes Cênicas, Universidade Federal do Rio Grande do Sul, this reflection reports the aspects of voice (spoken and heard) as a producer of expression and articulator of sense and presence. The meeting between voice, word and listening is discussed from studies of philosophy and theater according thoughts of José Gil, Gaston Bachelard, Roland Barthes, Ingrid Pelicori, Christoph Wulf, Jacques Derrida and Mladen Dolar.

Keywords: Voice; Listening; body; In between; actor

ISSN: 1414.5731

E-ISSN: 2358.6958

${ }^{1}$ Doutoranda no Programa de Pós-Graduação em Artes Cênicas da Universidade Federal do Rio Grande do Sul (UFRGS) - angilazzareti@gmail.com

2 Professora Dra. Associada do Departamento de Arte Dramática e do Programa de Pós-Graduação em Artes Cênicas (UFRGS) - mirna.spritzer@gmail.com 
Podemos afirmar que o corpo é expressivo por natureza. Expressividade revelada na forma de agir, pensar e, sobretudo, falar, fator que excede o ato de comunicarse enquanto premissa estruturada da linguagem. É como corpo que a voz será aqui contextualizada, considerando suas potencialidades de construção de sentido e de presença. Iniciamos a reflexão a partir das provocações do filósofo português José Gil:

O que é um corpo? É uma respiração que fala. [...] Enquanto o sopro se encara somente pelo seu lado puramente indicativo, ele é apenas a manifestação, rebatida no plano do tempo, de ritmos corporais; mas porque o sopro é uma mediação permanente entre o interior e o exterior do corpo, uma passagem, contem em si a própria possibilidade da expressão (sentido). [...] No entanto, não se deveria compreender esta mediação como, por exemplo, algo que permite ao sentido manifestar-se ou então (como parece pensar Husserl) permitindo que a camada indicativa da linguagem encontre o seu pleno desenvolvimento na expressão. Pelo contrário: ele não manifesta apenas as intensidades do corpo, mas constitui-as também como expressões. [...] É deste modo que o sopro se apresenta como uma espécie de princípio directivo dos ritmos corporais: como ele participa, do interior, na formação da expressão, esta reage sobre toda a camada indicativa do sentido- e, portanto, sobre o corpo: de tal maneira que o sopro- e a voz- aparecem como o que constitui o corpo em totalidade articulada no tempo (Gil, 1997, p. $88)$.

É possível distinguir que há sobre sopro, voz e corpo uma ligação entre ritmo e temporalidade que, de certa forma, agencia a produção da fala. O complexo de sons emitidos por nosso corpo é produto (e produtor) da atividade de cada célula e órgão do organismo, o que pressupõe um ritmo para sua existência que é singular para cada qual $^{3}$. Os estudos de Gaston Bachelard sobre a ritmanálise consideram o ritmo como a ondulação da vida e confirmam que até as formas mais aparentemente estáveis devem sua estabilidade "a um desacordo rítmico" (Bachelard, 1994a, p. 120). Em tudo há ritmo, essa energia vibratória é compreendida por Bachelard como a energia da existência. São também as vibrações ritmadas, produzidas entre as cordas vocais e a laringe em conexão com o cérebro e as demais partes do corpo, a base do processo de vocalização.

Além de pressupor um ritmo (que por si já pressupõe uma singularidade), a organização da passagem do sopro e da voz entre o corpo e o ambiente, molda a expressão, que no corpo, segundo Gil, é constituída dentre outros elementos, pela própria voz. O que quer dizer que a voz não é apenas um veículo para, mas criadora de expressão, tanto quanto expressividade manifestada. Para o filósofo, o ser humano é auto-significado pelo motivo de falar e ouvir-se em um mesmo movimento, junto à complexidade da construção de sentidos e presenças.

Porque fala- e se ouve- vivemos o nosso corpo numa presença imediata, nao-tética, inquestionável do seu sentido (que se confunde com o dia da sua/da vida): tem assim a unidade de um sentido que se vive (e não se pensa, não visa um objecto).

\footnotetext{
${ }^{3}$ Produzido no cérebro humano pelo Núcleo Supra Quiasmático, o ritmo circadiano é o que regula parte dos ritmos do corpo, sobretudo os biológicos, a partir da sua interação com o ambiente (reação às mudanças de temperatura, dia e noite, sensações de fome, etc.). Desse modo, é possível afirmar que os ritmos internos de um sujeito são como uma orquestra singular e ininterrupta, que funciona em interdependência entre todas as partes do corpo em sua relação com o ambiente externo, produzindo, portanto, reações e modos comportamentais distintos de um sujeito para o outro.
} 
A infralinguagem supõe um corpo auto-significado que se constitui pelo efeito da voz. [...] Estes corpos falam e, falando, dizem-se como unidades espontaneamente significadas organizadas numa coesão aquém do sentido dito, resultado de uma dupla transfusão em que a vida passa ao sentido de tal modo que este se apresenta como tão inquestionável, tão imanente como ela: e em que o sentido, impregnando a vida, a leva a uma total presença em relação a si própria, sem separação, sem transcendência. $O$ corpo pela sua voz, contém esta unidade da vida e do sentido (Gil, 1997, p. 88-89).

Todo falar alguma coisa é, antes, tocar a fala como corpo, apenas falando-se é possível falar. Do mesmo modo, escutar algo para um corpo é saber-se e sentir-se escuta no mesmo ato de escutar o que se está escutando. A voz é evidenciada como um elemento fundamental, não só na produção de sentido, mas também no modo como o sujeito se percebe, tangivelmente, como presença. Ao nos tocarmos, por exemplo, nos sentimos tocar desde dentro (o ato de: estou tocando) e, ao mesmo tempo, sentimos o toque desde fora (a percepção de: estou sendo tocado). Ao falar, produzimos a fala e, ao mesmo tempo, somos já invadidos pela fala produzida ao escutá-la. Dessa forma, experienciamos o corpo, e nesse caso o corpo-voz, em um contato de presença desde dentro e desde fora. Ao mesmo tempo em que produzimos essa presença como corpo que fala e escuta (em um mesmo movimento), a recriamos ao percebê-la como um toque meu em mim, já como um outro de mim.

Ao manifestar-se, a voz expressa e colabora na produção dos estados do corpo, exprime alegria, tristeza, prazer, medo, etc. Isso porque a voz está em contato direto com o que a atriz e pesquisadora Ingrid Pelicori chama em Caligrafía de la voz de "música da paisagem interior"4 (Pelicori, 2007 p. 3). Um conjunto entre imaginação, memória, percepções e possibilidades do sujeito, que são transmitidos, mesmo que de maneira involuntária, através da colaboração entre voz e palavra. Poderíamos pressupor então que, ao dizer e dizer-se, o sujeito está criando, comunicando e ao mesmo tempo se encontrando com a música dessa paisagem. E podemos considerar ainda, que ao percebê-la, já passa a recriá-la mais uma vez. Nesse ponto, o corpo titulado por Gil como auto-significado pode também ser refletido como auto-presença, sendo para si presente no encontro entre o corpo-voz que falando-se fala e, por conseguinte, toca-se ao escutar a escuta que apresenta essa paisagem como outra.

Para Pelicori, a voz possui o poder de desvendar e revelar "o mistério do corpo que fala, aquilo que resiste a uma significação, [...] que não se pode descrever, e que nos toca justamente por não compreendermos"5 (Pelicori, 2007 p. 36). Assim, uma relação entre nexo e enigma se estabelece entre o dito e o não dito. A subjetividade do sujeito é envolvida no dizer que foge do controle voluntário do que deve ou não ser revelado juntamente com a palavra dita. "A voz como uma coruja selvagem, suspira na gaiola do coração" (Bachelard, 1994b, p. 34). O estudioso e semiólogo Roland Barthes, em O óbvio e o obtuso, também explana de forma esclarecedora sobre este fator:

Escutar alguém, ouvir sua voz, exige por parte do observador, uma atenção aberta

\footnotetext{
4 "música del paisaje interior". (Tradução nossa)

5 "Misterio del cuerpo que habla, lo que resiste a la significación, [...] que no se puede inscribir, que nos emociona porque no la comprendemos". (Tradução nossa)
} 
a esse intervalo entre corpo e o discurso. O que é oferecido para ser ouvido por essa escuta é exatamente o que o individuo não diz: a trama inconsciente que associa seu corpo como espaço de seu discurso: trama ativa que ritualiza na palavra do individuo a totalidade de sua historia (Barthes, 1990, p.224).

Sabe-se que a palavra por si já "quer dizer" algo, e que existe ainda um sujeito que através dela "quer dizer" algo que pode redirecionar e transformar o primeiro "quer dizer" da palavra. E mais ainda, alguns "quer dizer" que estão ocultos sobre os primeiros. A palavra deixa de ser propriedade do significado no momento em que a voz toca cada letra com o inevitável contágio que todo contato desencadeia. Todo "quer dizer" instituído pode ser excedido quando há a presença da voz e da escuta. A palavra assume variados sentidos que se somam ao sentido próprio, que o enfatizam, contrariam e transformam seus saberes habituais. A presença da voz desestabiliza o significado como dado fixo, apela mais ao sentido se pensado de forma dupla, incluindo aquilo que é sentido como corpo: fala que se sente fala quando escuta e escuta que se sente escuta quando fala. "A voz é um gesto fonético, que produz um som habitado de sentido, moldado pela experiência, onde a linguagem é invadida de presença, em que se revela uma subjetividade"6 (Pelicori, 2007, p. 36).

É possível refletir sobre um mundo revelado e outro escondido sob as palavras, pois conforme são combinadas com fatores da memória, imaginação, estados corpóreos e contexto presente modificam os sentidos e produzem diferentes estímulos. É por esse motivo que a mesma palavra dita por duas pessoas não terá o mesmo sentido particular e provocará distintos afetos. A voz movimenta traços íntimos do sujeito, uma vez que a memória e a imaginação participam da vocalização das palavras, as somando a outros elementos e revelando outras possibilidades de existência de uma palavra única que passa a possuir incontáveis facetas mais.

Também destacamos aqui, que a característica utilitária da voz (falada e escutada) em prol da linguagem, ainda que seja o modo pelo qual a experimentamos habitualmente, não pretende alcançar o que a voz é. A potência existente aí acaba reduzida por um condicionamento perceptivo sobre o que se compreende por voz, sempre em relação ao que ela "serve". Abrangendo processos de complexidade comunicacionais e comportamentais, sabemos que a linguagem é mais que a voz, envolve camadas objetivas e subjetivas extensas que ascendem aos códigos e símbolos fixados social e culturalmente para a interação entre os sujeitos. Entretanto, mesmo sem o intuito da partimentação entre voz, fala e linguagem, podemos visualizar sem dificuldades que a voz participa quase como protagonista do processo comunicacional estruturado. Afirmamos, por outro lado, que, assim como a linguagem excede a voz, a voz também excede a linguagem.

É possível falar ainda de comunicação, considerando aquilo que extrapola os reguladores tradicionais, ultrapassando a ideia de transmissão de informações, atingindo outras possibilidades de experiência. Além da característica de movimentar o sentido das palavras, desestabilizando seus significados, a materialidade da voz como presença estimula reflexões mais profundas a respeito das relações existentes na prá-

\footnotetext{
6 "La voz supone un gesto fonético que produce un sonido habitado por el sentido, moldurado pela experiencia, donde el lenguaje está invadido de presencia y en el que se revela una subjetividad". (Tradução nossa)
} 
tica banal que é falar e escutar e sobre o toque duplo entre esses processos. Trata-se de algo que existe, mesmo com a linguagem, mas que existe também, sem ela (talvez disparando outros modos de existência para ela). A voz é corpo antes de pertencer à linguagem, é presença antes de formar sentido, ou seja, está antes de ser. Fala e escuta são aqui refletidos como movimentos, promovem encontros e estimulam experiências de comunicação que recriam e alargam a própria noção tradicional de comunicação.

Para Bachelard (1978, p.314), "A voz, ser frágil e efêmero, pode testemunhar as mais fortes realidades.[...] Mas, antes de falar, é preciso ouvir". Conforme o percurso transcorrido até aqui, a impossibilidade da separação entre falar e escutar já foi evidenciada. O ser humano só fala porque ouve, para o pesquisador Christoph Wulf (2007, p. 2) em O ouvido "ouvimos a fala antes de falar e entender. Ouvir, desse modo, é a condição para entender e falar". O sentido da audição não cessa. Os ouvidos não dormem, não fecham os olhos, não têm pestanas. Esse ouvir está ligado a um ato fisiológico do ser, já o escutar é um ato psicológico que se mescla à percepção, apropriação e recriação. Este escutar é ser "tocado" pela fala, portanto, por quem fala. Aqui podemos refletir sobre a materialidade da voz, que subjetiva e objetivamente, pressupõe um contato, não só psicológico, mas também físico (para além das ondas sonoras que tocam a pele). Conforme Barthes (1990, p. 224): "A escuta da voz inaugura a relação com o outro". Desse modo, a escuta da voz, junto ao toque pela fala, também concretiza o encontro do sujeito consigo como um outro, pois escutamonos desde dentro e também desde fora.

Assim, é possível refletir sobre essa escuta como uma ação ativa e produtora de presença, onde ocorre o encontro entre o que diz e o que escuta. Considerando também, como parte desse processo, a apropriação, a interpretação e a recriação daquilo que foi dito. O sentido primeiro da palavra já repleto de sentidos impregnados por quem fala, é transformado ainda pela escuta que se deixa invadir primeiramente por um novo saber e, por consequência, o soma a seus próprios saberes. Ao escutar, o som proferido se funde ao íntimo daquele que escuta em reverberação dinâmica, estimulando associações e as modificando no presente, assim, ideias, imagens e sensações são produzidas junto a uma nova presença que surge ao unir a palavra dita com a percepção acionada pela escuta. O filósofo Jacques Derrida, em sua obra $A$ voz e o fenômeno, onde evidencia a voz como princípio fundamental, relata:

Falar a alguém é, certamente, ouvir-se falar, ser ouvido por si, mas também, e, por isso mesmo, se se é ouvido pelo outro, fazer com que ele repita imediatamente em si o ouvir-se-falar na mesma forma em que eu o produzi. Repeti-lo imediatamente, isto é, reproduzir a auto-afeição pura sem o auxílio de nenhuma exterioridade. Essa possibilidade de reprodução cuja estrutura é absolutamente única, se dá como o fenômeno de um domínio ou de um poder sem limites sobre o significante (Derrida, 1994, p. 90- 91).

Ao analisar a voz em sua constituição de presença, relação com o signo, silêncio e inconsciente, Derrida (1994, p. 90) deixa claro que "uma ciência 'mundana' objetiva não pode nos dizer nada sobre a essência da voz". Ainda assim, é possível e instigante analisar o fenômeno da voz como constituinte do sujeito em sua corporeidade. Enfocando as relações de toque que a voz desencadeia como acesso de um sujeito a 
outro e a si, a voz acessa a própria voz como lugar no tempo de um corpo que escuta e diz. Escutar é dizer e dizer é escutar. Logo, entre sentidos e presenças, ao dizer, é um outro corpo que escuta, ainda que seja como o mesmo (que já não é ao ouvir). Movimento duplo no qual a voz é acesso de contato entre sujeitos que experienciam na escuta a voz do outro em si, contágio entre um e outro. Aquilo que passa de boca em boca, de ouvido em ouvido, não apenas passa sem que um experimente, em contato, o outro. Dessa forma, entre o que é dito e o que é escutado, nunca há só uma voz. É Bachelard em A agua e os sonhos que toca a potencialidade voz.

E a alegria de exprimir é tão exuberante que, em última análise, é a expressão vocal que marca a paisagem com seus "toques" dominantes. A voz projeta visões. Lábios e dentes produzem então espetáculos diferentes. Há paisagens que são criadas com os punhos e os maxilares... Há paisagens labiadas, tão suaves, tão boas, tão fáceis de pronunciar... Em especial, se pudéssemos agrupar todas as palavras com fonemas líquidos, obteríamos naturalmente uma paisagem aquática. Reciprocamente, uma paisagem poética expressa por um psiquismo hidrante, pelo verbo das águas, encontra naturalmente as consoantes líquidas. $\mathrm{O}$ som, $\mathrm{o}$ som nativo, o som natural - isto é, a voz - , põe as coisas no seu lugar. A vocalização comanda a pintura dos verdadeiros poetas (Bachelard, 1998, p. 196-197).

Ao refletir sobre o corpo-voz, incluímos aqui a contribuição desse pensamento sobre o trabalho do ator. O ator que experiencia a sua voz nos processos criativos, não apenas como um veículo de informações tecnicamente manipulável, mas como produtora de expressão, explora a produção de sentidos e presenças. Por ter como sua arte o saber sensivel dos sentidos e fazê-los significar em seu corpo, o ator possui a vocação para a palavra, para o dizer, para encontrar na composição das frases, a beleza dos sons e dos andamentos. São experiências como essas que exigem a voz implicada na produção do dizer, mas na mesma medida dirigida para o outro que escuta.

Abre-se dessa forma, um mundo de possíveis sonoridades, sentidos e imagens que possuem o poder de tocar tangivelmente aquele que escuta. Há um destino para essa fala, ela está destinada à escuta, se apresenta assim como um gesto a ser partilhado entre o ator e o espectador. $O$ ator trabalha não apenas sobre as potencialidades do dizer, mas a escuta sobre o outro e sobre si é fundamental para o encontro entre os atores que contracenam, dos atores com o público e do processo de presentificação do ator junto ao espectador. O corpo-voz anuncia a multiplicidade existente na palavra proferida e escutada, munida de intensidades que colaboram para o acontecimento teatral. Os atores atuam com todo o foco na escuta de si e do outro. É perceber na prática a vivência de ser um e outro ao mesmo tempo, ator e ouvinte, podendo assim tomar as rédeas de sua atuação no instante mesmo da sua realização. A contracenação, assim, acontece via escuta. É um momento claro em que se abandona a necessidade do olhar ou do movimento em favor de dizer e ouvir. O foco da ação vocal se dá na troca entre vozes, silêncios e do engajamento corporal na presença da voz.

A palavra em movimento é compreendida como ação. No trabalho de atuação, o ator lê o mundo e dele cria um texto feito de carne, sons, silêncio, movimento, respiração e sangue. O corpo é mente e a voz é corpo. Como uno, o corpo-voz com- 
preende um fenômeno de expressão e inscrição de sentidos e presenças, tenciona a subjetividade do sujeito (que fala e que escuta), movimentando-a em devir. No trabalho do ator, a visão de tal proposta culmina na criação de possibilidades expressivas, toca-se o outro que escuta, toca-se a si, estimulando um contato tangível fundado na presença de um corpo-voz que produz e produz-se na ação da palavra.

Podemos perguntar ainda, enquanto conclusão inconclusa: onde está a voz?

Nossa hipótese é a de que a voz está sempre em um entre, pois precisa ser produzida/dita para existir e, ao ser proferida, já excede a fronteira do corpo que disseque já a lançou para fora de si e, simultaneamente, escutou-se. Já invadiu o mundo e foi por ele invadida. Entre o dentro e o fora de um ser que é o eu e ao mesmo tempo o outro. Seria a voz, inspirada pela citação de Gil, um sopro em comum entre o sujeito e o outro, o ser e o mundo?

Segundo o estudioso da voz Mladen Dolar, a voz não pode ser descrita linguisticamente, pois isto seria reduzi-la. "A voz é outra coisa: é na linguagem aquilo que não contribui a significação; é o que não ajuda a fazer sentido. E isso poderia servir como sua definição provisória- é o que não pode ser dito, ainda que torne possível o dizer"7 (Dolar, 2014, p.5). A dificuldade em alcançar a voz estaria em sua topologia, sua localização entre o dentro e o fora. O filósofo corrobora com essa reflexão explanando que ainda que a voz emane de dentro do corpo, ela é também uma parte do mundo que não cabe ao controle do sujeito que a proferiu, torna-se um projétil de trajetória própria. Dolar estuda sobre uma voz que não pode ser tida enquanto posse (a minha voz), mas antes uma voz que fala em e através do sujeito- que é falado ao falar. A voz encarna a conjunção entre presença e sentido e é uma experiência, segundo o filósofo. Esta concepção aproxima-se da reflexão de Gil quando discorre que a voz faz o sujeito vivenciar o seu corpo em uma presença imediata. Dolar, ao explanar que a "voz encarna presença", refere-se ao aspecto de temporalidade incluso aí. Afirma que a voz é o paradigma do transitório, em um constante devir e transcorrer, estando relacionada com a noção de tempo e o nosso permanecer em presença.

Segundo Dolar, a voz funda um entre dois, contribuindo para a ideia a respeito da presença entre do corpo-voz. Ainda defendemos aqui, a tese sobre uma ideia de presença relacionada ao acontecimento teatral, de um modo distinto do qual temos conhecimento, que habitualmente confere a presença à atuação do ator. Essa presença da qual discorremos, não estaria no ator que profere (capacidade de reter atenção, de encantar o outro). Tampouco no espectador que escuta (mundo subjetivo de criação/recepção). A presença, nesse caso, refere-se a um estado partilhado entre o que diz e o que escuta, a existência de algo em comum que produz a "coisa dita-escutada" e produz os próprios corpos que dizem-escutando, já que, com o apoio de Gil, temos que a voz não apenas veicula expressão, mas a produz como corpo. Presença que até hoje não pôde ser precisamente localizada e isso se deve, justamente, porque é antes uma relação que uma coisa.

A voz vem do outro sem ser parte dele; Voltamos a essa ambígua ontologia- ou

\footnotetext{
7 "La voz es otra cosa: es en el lenguaje aquello que no contribuye a la significación; es lo que no ayuda a hacer sentido. Y esto podría servir como su definición provisoria - es lo que no puede ser dicho, aun que hace posible el decir". (Tradução nossa)
} 
melhor, topologia- do estatuto da voz como um "entre dois", situada precisamente na curiosa intersecção. A voz se pode localizar na conjuntura entre o sujeito e o Outro, em um registro diferente do utilizado antes, quando a situamos na intersecção entre o corpo e a linguagem, circunscrevendo uma falta em ambos. Ao esquema empregado anteriormente, poderíamos dar um novo uso. A voz é o elemento que une o sujeito e o Outro, sem pertencer a nenhum dos dois, assim como formou o laço entre o corpo e a linguagem sem ser parte deles ${ }^{8}$ (Dolar, 2007, p.39).

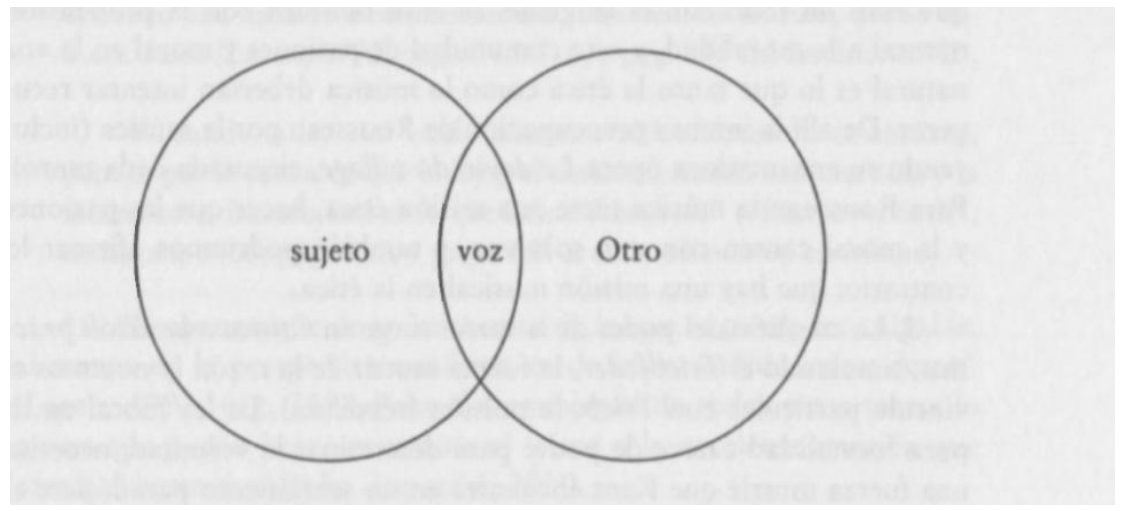

Figura I (Dolar, 2007, p. 39)

Dolar esclarece que não é possível dividir a presença da voz, seccioná-la. Com relação à música da paisagem interior refletida por Pelicori, Dolar aclara que o incorpóreo trata-se da quintessência da corporeidade- junto a garganta, a saliva, a carne e a memória, a intenção, a imaginação. A voz excede o corpo, mas se a voz é corpo, tratamos aqui de um corpo que excede o corpo ou de uma outra ideia de corpo que engloba camadas visíveis e invisíveis.

Aqui temos a fantasia que rodeia a voz em sua forma pura: há uma discrepância entre a pessoa e a voz, mas o caráter único da voz traz a luz o que na pessoa existe mais que ela, o tesouro interior, a parte mais genuína, a quintessência do único, a pura exteriorização do mais íntimo. A voz, separando-se da pessoa, expandindose no ar como sua carta invisível é mais real que a pessoa em si mesma. É essa exceção que produz uma nova e intensiva classe de presença, dotada com o poder enigmático que porta a voz $^{9}$ (Dolar, 2014, p. 17).

Prosseguindo o raciocínio, a voz encontrando-se entre o dentro e o fora, jamais será unicamente a paisagem interior de um sujeito. Ao mesmo tempo em que é a expressão de sua singularidade, é também uma intrusa que pulsa fora dessa paisagem e que a rompe, invade-a transformando a si própria e o sujeito. Entre a natureza e a cultura, o biológico e o simbólico, o sujeito e o outro, a interioridade e a exterioridade- a voz está sempre na intersecção entre ambos e ao habitá-los também os produz, pois não se trata de uma existência independente e fragmentária de cada uma das

\footnotetext{
8 "La voz viene del Otro sin ser parte de él; Hallamos de nuevo esta ambigua ontología -o, más bien, topología- del estatuto de la voz como un "entre dos", situada precisamente en la curiosa intersección. A la voz se la puede ubicar en la juntura entre el sujeto y el Otro, así como antes, en un registro diferente, se la sitúo en la intersección entre el cuerpo y el lenguaje, circunscribiendo una falta en ambos. Al esquema empleado anteriormente puede dársele un nuevo uso. La voz es el elemento que une el sujeto y el Otro, sin pertenecer a ninguno de los dos, así como formó el lazo entre el cuerpo y el lenguaje sin ser parte de ellos." (Tradução nossa) 9 "Acá tenemos la fantasía que rodea a la voz en su forma pura: hay una discrepancia entre la persona y la voz, pero el carácter Único de la voz saca a la luz lo que en la persona es más que ella, el tesoro interior, la parte más genuina, la quintaescencia De lo único, la pura exteriorización de lo más íntimo. La voz separándose de la persona, esparciéndoseenel aire como su Misiva invisible, es más real que la persona en sí misma. Es esta escisión la que produce una nueva e intensiva clase de presencia, dotada con el poder enigmático que porta la voz". (Tradução nossa)
} 
partes. Dessa forma, a voz opera não separando duas partes distintas, mas as criando também.

Incluímos na discussão, a inspiração em Martin Heidegger que afirma que a ponte não é apenas o que separa ou une as margens de um rio, mas o que faz com que as margens surjam como margens. Tratamos nessa reflexão, a partir dos estudos realizados, de presenças habitadas por sentidos e de sentidos habitados por presenças, corpos habitados pelo mundo e o mundo habitado pelos corpos. Para Dolar, falar a respeito da voz é falar do ponto no qual o sentido encontra-se com a carne. "É por isso que o objeto voz, que pertence a experiência mais comum, ao mesmo tempo aponta a um paradoxo ontológico, por assim dizer, requer uma nova classe de topologia e uma nova classe de ontologia"10 (Dolar,2014, p. 29-30).

A ideia que inspira o presente artigo e que continuamos a busca por delinear é sobre um ser, que a exemplo do corpo-voz, pulsa na esfera do entre e que na perspectiva do acontecimento teatral, promove um estado de presença partilhada entre ator e espectador na produção conjunta e em curso do acontecimento e dos próprios sujeitos. Entre o dentro e o fora, a presença e o sentido, eu e o outro, o real e o ficcional, o visível e o invisível- entre.

\section{Referências}

BACHELARD, Gaston. A dialética da duração. São Paulo: Editora Ática, 1994a.

BACHELARD, Gaston. A filosofia do não; O novo espírito científico; A poética do espaço / seleção de textos de José Américo Motta Pessanha. São Paulo: Editora Abril Cultural, 1978.

BACHELARD, Gaston. A poética do devaneio. São Paulo: Editora Martins Fontes, 1988.

BACHELARD, Gaston. Fragmentos de uma poética do fogo. São Paulo: Editora Brasiliense,1990.

BACHELARD, Gaston. O direito de sonhar. Rio de Janeiro: Editora Bertrand Brasil, 1994b.

BARTHES, Roland. O óbvio e o obtuso. Rio de Janeiro: Nova Fronteira, 1990.

DERRIDA, Jacques. A voz e o fenômeno: Introdução ao problema do signo na fenomenologia de Husserl. Rio de Janeiro: Editora Jorge Zahar, 1994.

DOLAR, Mladen. Una voz y nada más. Buenos Aires: Manantial, 2007.

DOLAR, Mladen. Que hayen una voz? 2014, disponível em: http://www.psicoanali-

\footnotetext{
10 "Es por esto que el objeto voz, que pertenece a La experiencia más común, al mismo tempo apunta a una paradoja ontológica, por así decirlo, requiere una nueva clase De topología y una nueva clase de ontología".(Tradução nossa)
} 
sisysociedad.org/Textos/2014/M-Dolar-Que_hay_en_una_voz.pdf

GIL, José. Metamorfoses do Corpo. Lisboa: Editora Relógio D’Água,1997.

HEIDEGGER, Martin. Ensaios e conferências. Petrópolis. Editora Vozes, 2002.

PELICORI, Ingredi. In: ALDABURU, Maria; BANEGAS, Cristina; HERRERO Liliana; PELICORI, Ingrid; SCHVARTZ, Claudia. Caligrafía de la voz. Buenos Aires: Editora Leviatán, 2007.

WULF, Christoph. O ouvido. Ghrebh- 9. Revista de Comunicação, Cultura e Teoria da mídia, 2007.

Recebido em: 06/09/2016

Aprovado em: 06/11/2016 